\title{
Biotech stocks cushioned from Cephalon setback
}

Cephalon's (Westchester, PA) announcement last June of positive results in its 236-person North American phase II/III trial of Myotrophin (insulin-like growth factor, IGF1) for amyotrophic lateral sclerosis (ALS) was acclaimed by many as the beginning of, if not an actual trigger for, the biotechnology stock rally in the second half of 1995. So when the U.S. Food and Drug Administration (Rockville, MD) told the company on January 18 that it would not grant a treatment investigational new drug (tIND) application for Myotrophin because of concerns that the European clinical trial results did not support the earlier North American trials, companies and investors held their breath anxiously.

Ironically, in November 1995, right after Cephalon announced its now-controversial European results and filed for a tIND, company CEO Frank Baldino Jr. predicted that "if Myotrophin [and other pending products] get approved in 1996, the sector will do well. . .which will bring new capital into the marketplace. If there are bumps along the road, and if we or others are not successful in our quest for drug approval, it will look more like 1994 than 1995."

Most analysts now seem to think, however, that the FDA's rejection of Cephalon's tIND will affect neither general biotechnology stock recovery nor individual company stock prices [beyond those directly affectedCephalon and its U.S. partner, Chiron (Emeryville, CA)]. Some also think that Cephalon will be able to file for a new drug application (NDA) within six months after addressing the FDA's concerns, and that Myotrophin will be approved by year's end.

"The market is showing signs of maturity," says Salomon Bros. (New York) analyst, Meirav Chovav. "Cephalon may have opened up the market in June, but its latest news hasn't ended the rally." While the failure of one product, such as Synergen's (Boulder, $\mathrm{CO}$ ) Antril for sepsis, was enough to send the sector into a tailspin in 1993, that won't happen now, Chovav asserted, as investors increasingly focus on companies' fundamentals.

Peter Ginsberg of Vector Securities (Deerfield, IL) agrees with Chovav, calling Cephalon's drop in stock price, "a hiccup." Of more weight, he says, is the number of late-stage trials that will yield positive results in the next half-year, such as ImmuLogic's (Cambridge, MA) phase III AllerVax trials and La Jolla Pharmaceutical's (San Diego,

Michelle Glenn is a freelance writer in New York. John Hodgson is a senior editor at Nature Biotechnology.
CA) phase II with LJP-394 for lupus. January's positive results from phase III trials with Agouron's (La Jolla, CA) and Merck's (Rahway, NJ) "rationally designed" protease inhibitors in AIDS are also robust signs for biotechnology.

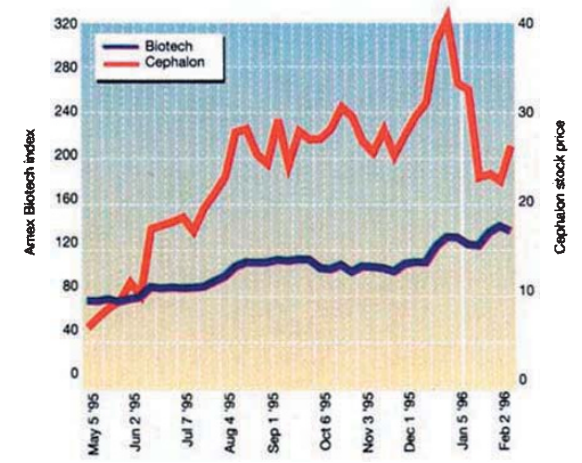

Cephalon returns to blotechnology reality. After Himalayan stock price sorties, Cephalon stock has realigned itself with the Amex Biotech Index.

While Cephalon's stock fell about $40 \%$ in January, according to David Stone of Cowen $\&$ Co. (Boston), the stock of 26 companies he covers rose an average of $18 \%$ during the same period. According to one source, a total of $\$ 250$ million in new funding was raised in the week ending February 5 alone, and $\$ 407$ million in the first five weeks of 1996. "At this point, I would be very surprised to see even a top-tier company's trial move the entire market," Stone commented, noting that even
Amgen's (Thousand Oaks, CA) less-thanspectacular October 1995 trial results with Neupogen in community-acquired pneumonia didn't affect the rally. "There are enough horses in race now so that if one stumbles, it shouldn't pull down the entire field," he added.

With Cephalon's stock price down, a good number of analysts think the company is now a good buy, assuming an almostworst-case scenario: Myotrophin is approved and launched after a delay of two years, if the FDA wants an additional clinical trial. Others, like Vector's Ginsberg, strongly believe it will be approved in a timely manner. Even if it is not approved, analysts point to Cephalon's strong neuroscience pipeline, and believe the biotechnology sector as a whole will continue to perform well.

In a recent overview of the industry, Morgan Stanley's (New York) Eric Hecht predicts a secondary rally for biotechnology stocks in the second half of 1996 . He estimates that over 20 drugs are either under FDA review or poised for filing, and an additional 20 will complete phase III trials this year. With as many as 10 new drugs coming to market in 1996 and double that number in the next two years, the rise and fall of the market with the fortunes of one drug, or one company, may be a thing of the past.

Michelle Glenn John Hodgson

\section{Myotrophin: "spectacular" or "snake oil"}

In the weeks following the U.S. Food and Drug Administration's (FDA, Rockville, MD) denial of Cephalon's treatment investigational new drug (tIND) application, speculation was rife about the quality of Cephalon's European Myotrophin data. Neither the FDA nor the company has discussed the issue, and as of early February, they had neither met nor set a meeting time to discuss the data. On January 19, a number of shareholders brought a class action suit against Cephalon. They alleged that management had knowingly misrepresented data from both trials with Myotrophin, calling results "spectacular," while withholding or underplaying the number of deaths in the European trial, and claiming that the drug had an effect on survival. These claims, say the litigants, resulted in a bolstering of stock price, and large profits for Baldino and vice-president R. Edward Branson, who sold large numbers of their shares during this period. Cephalon would not comment.

Stock analysts' views on the trial data differ enormously. UBS Securities (New York) analyst Tim Wilson believes that Myotrophin is safe and efficacious beyond a doubt, and although the FDA was comfortable with earlier results from the North American trial, "it does have substantive issues regarding the European equivalent"-namely, whether those data supported the North American results. The fatality rate in both trials was very similar: 23 of the 236 patients in the North 